\title{
Landscape analysis of the family planning situation in Pakistan: Brief summary of findings
}

Population Council

Follow this and additional works at: https://knowledgecommons.popcouncil.org/departments_sbsr-rh

Part of the Demography, Population, and Ecology Commons, Family, Life Course, and Society Commons, and the International Public Health Commons How does access to this work benefit you? Let us know!

\section{Recommended Citation}

"Landscape analysis of the family planning situation in Pakistan: Brief summary of findings." Islamabad: Population Council, 2016. 


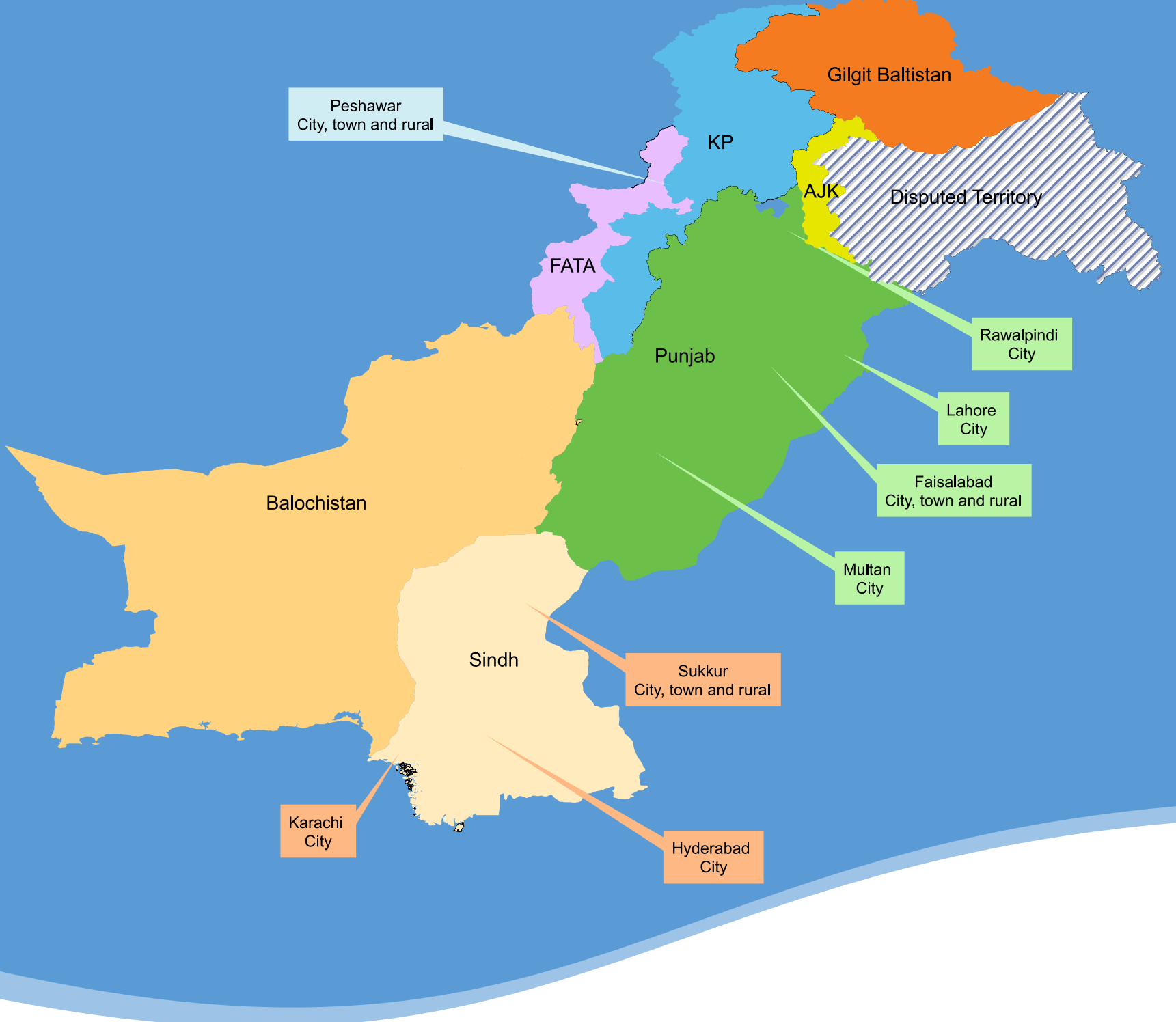

\section{LANDSCAPE ANALYSIS OF FAMILY PLANNING SITUATION IN PAKISTAN} BRIEF SUMMARY OF FINDINGS

September, 2016

BILL\& MELINDA

GATES foundation
POPULATION COUNCIL

Ideas. Evidence. Impact. 



\section{Table of Contents}

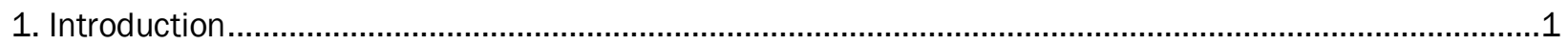

2. Potential for and Barriers to Growth in the Family Planning Market......................................................

3. Provision of Family Planning Services and Barriers to Growth ..........................................................

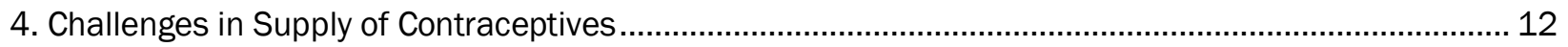

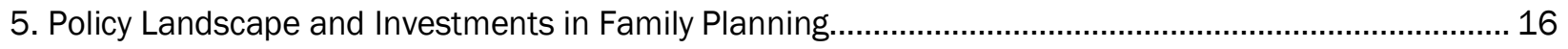

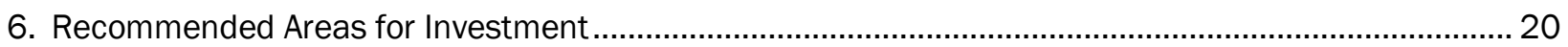





\section{Introduction}

The "Landscape Analysis of the Family Planning Situation in Pakistan" was carried out by the Population Council with the support of the Bill and Melinda Gates Foundation in 2015-2016. The analysis provides a comprehensive assessment of consumer demand, contraceptive service provision, and contraceptive supply, and the provincial policy environment based on primary data collection in eight districts in Punjab, Sindh, and Khyber Pakhtunkhwa. Its aim is to identify investment opportunities to catalyze an escalation in contraceptive prevalence, enabling Pakistan to meet its FP2020 goals.

\section{A Challenging Context}

Pakistan faces a number of challenges to increasing modern contraceptive use. Although there are encouraging signs-growing male participation; almost 3 million additional current users from 2007 to 2013; and a more responsive policy environment-the task that lies ahead is huge. While 55 percent of currently married women of reproductive age have tried a contraceptive method at some point in their lives, only 35 percent are currently using any method, with even fewer, 26 percent, using modern methods. Discontinuation rates are especially high for the intrauterine device (IUD), and use of hormonal female methods is either stagnant or declining. Meanwhile, around 2.1 million abortions are induced annually to avoid unwanted pregnancies.

On the supply side, there is a daunting gap in service coverage in most parts of the country, including a semi-functional public health sector which is not fully responsible for family planning in its service package, along with sub-optimal provision of family planning in the private sector.

\section{Objectives of the Landscape Analysis}

The objectives of the study are to:

1. Provide a comprehensive assessment of the coverage of family planning services, the constraints of different segments of consumers, the limitations of contraceptive choice, and opportunities to expand access and choice through a market segmentation approach;

2. Identify, analyze, and address supply and demand barriers in the public and private sectors;

3. Assess the market for commodities and services for family planning, especially, suppliers' perspectives;

4. Assess the policy landscape and scale of donor investments in family planning; and

5. Make suggestions about future strategies and areas of investment for family planning in three provinces in Pakistan, i.e., Punjab, Sindh, and Khyber Pakhtunkhwa.

\section{Study Location}

Primary data collection for the landscape analysis was carried out in 2015-2016 in eight districts of three provinces of Pakistan, including the cities of Peshawar in KP; Rawalpindi, Faisalabad, Lahore, and Multan in Punjab; and Sukkur, Hyderabad and Karachi in Sindh. In addition, we conducted investigations at one town and one rural location within one district in each province, specifically, Peshawar, Faisalabad, and Sukkur, and the availability of family planning services was mapped in its entirety in these three districts. 


\section{Study Components and Methods}

Beginning with an intensive secondary data analysis, documented in a separate report, the landscape analysis study consisted of five primary research components, the methodologies of which are briefly indicated below.

Our Approach to the Landscape

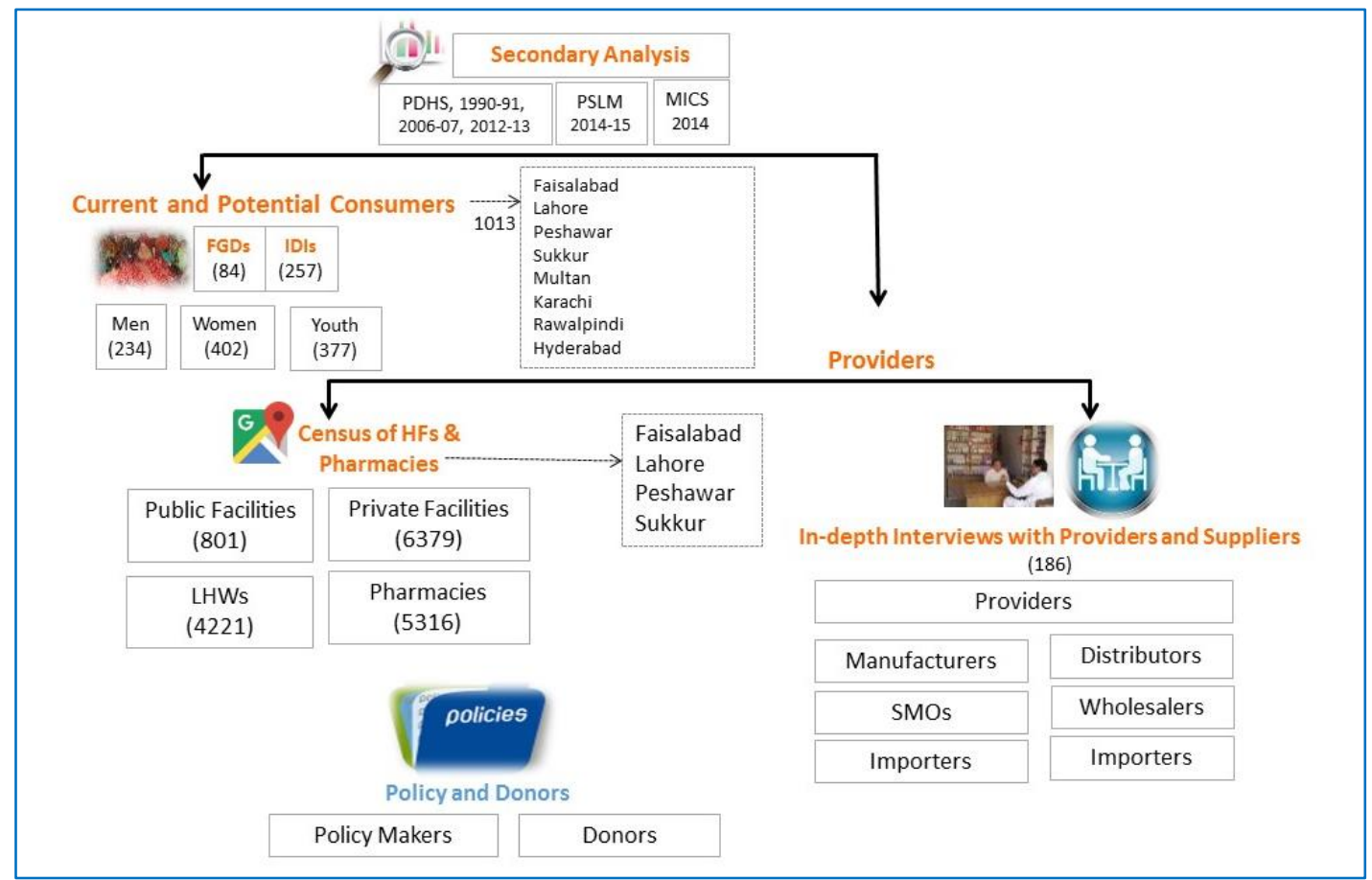

Qualitative study on consumer demand for family planning: This comprehensive study entailed 257 indepth interviews (IDIs) and 84 focus group discussions (FGDs) with a total of 1,013 respondents, including married men and women and unmarried youth in all 14 study locations. Its purpose was to extend and deepen the consumer profile developed during the secondary analysis, and further probe demand for family planning; current and potential consumers' social networks and communication channels; barriers of different segments; and consumers' receptivity to the relatively new methods, i.e., the Standard Days Method, Sayana ${ }^{\circledR}$ Press, implants, and emergency contraceptive pills (ECP).

Breaking the mold of previous studies in Pakistan that focus on married women and men, the study also sought the perspectives of single young people (aged 16 to 20 years), including school-going as well as out-of-school boys and girls, to explore the perspectives of these future potential users on family planning. A total of 206 girls and 171 boys participated in 22 and 20 FGDs, respectively.

Mapping and assessment of health facilities: This large undertaking was essentially a census of public and private health facilities $(7,180)$ and pharmacies $(5,316)$ in the Faisalabad, Sukkur, and Peshawar districts, as well as three towns of Lahore (Samanabad, Data GunjBux, and Shalimar). A total of 12,496 interviews were conducted to assess provision of family planning services, as well as accessibility, readiness, and quality aspects. The presence of Lady Health Workers was also mapped. The primary aim was to examine existing coverage of family planning services and potential for expansion. Data from a similar earlier exercises in Multan and Karachi has also been incorporated to develop district profiles. 
The Population Council used Android-based mobile devices to collect data through face to face interviews with healthcare providers and pharmacists. Data collection through mobile devices provided instant access to data being collected in the field to study manager, and greatly helped in monitoring the field to improve data quality. Since data uploading was instant, the online monitoring of the data and movement of the field teams helped in ensuring speed and quality of data collection. Data was downloaded and exported into Excel for initial cleaning, etc., and then exported to SPSS for detailed analysis.

Qualitative study of contraceptive supply in the private sector: This study sought to understand availability of contraceptive products and their supply flows and constraints in the less known private sector contraceptive supply system. It involved 107 interviews in Lahore, Faisalabad, Karachi, Sukkur, and Peshawar with major contraceptive importers, manufacturers, and social marketing organizations; formal distributors and wholesalers; and proprietors/staff at pharmacies and shops. In addition, 79 interviews were conducted with various cadres of service providers.

A total of 186 IDIs with various cadres of providers and tiers of suppliers were conducted to assess supply of contraceptives as well as constraints and bottlenecks. In this regard, interviews were conducted with representatives of 16 major contraceptive importers, manufacturers, and social marketing organizations; 10 major distributors and 18 wholesalers of contraceptives; and owners or staff at 24 pharmacies, 24 general stores, and 22 paan shops (kiosks), including outlets that were selling contraceptives as well as those that were not.

Among the service providers interviewed were 25 male and female doctors, 18 Lady Health Visitors (LHVs), 16 dispensers, and 20 hakeems and homeopaths, including providers as well as non-providers of family planning services.

Review of the policy environment and donor mapping: This exercise was conducted to identify policy and programmatic gaps and map donor investment in Pakistan. The analysis of the policy environment examines the current family planning policy milieu with regards to the Health and Population sectors, existing legislation to improve the health and wellbeing of women and families, and the regulations being applied to standardize public private sector services. The analysis commenced with a desk review of population and health policies and strategies; growth strategies, vision documents, and related road maps; relevant legislation; relevant reports and publications. This review was followed by qualitative interviews with key stakeholders, including senior policy makers, representatives of donors, development partners, and NGOs, commercial sector representatives, government officials, program managers, etc.

The donor mapping activity was carried out to identify the major donors who are working in Pakistan in the area of reproductive health/family planning and to geographically map the major projects and activities being implemented in each province and district. The methodology included a desk review of existing donor profiles developed by UN agencies and information available on donors' websites. This helped in identifying and listing those donor organizations that have a social sector mandate. These organizations were then approached and the existing information was verified and expanded through face-to-face and telephonic interviews. A pro forma questionnaire was also sent out that was duly filled in by the relevant representatives of the development partners to get information about their existing donor supported projects, the thematic focus being pursued in the area of family planning and reproductive health, the geographical areas by province where they are working, a brief description of the project activities, implementing partners (if any), and the total budget allocated. 


\section{Potential for and Barriers to Growth in the Family Planning Market}

\section{There is potential to double the current market for modern contraceptives.}

Of the estimated 31 million married women of reproductive age (15-49 years) in Pakistan, only 8.1 million are currently using modern contraceptives. However, if users of traditional methods, and never and past users with unmet need would use modern contraceptives, the market would swell to 17.2 million. This would raise Pakistan's modern contraceptive prevalence rate (mCPR) from the current $26.1 \%$ to $55.5 \%$.

\section{Growth Potential among Current, Past and Never Users of Family Planning in Pakistan}

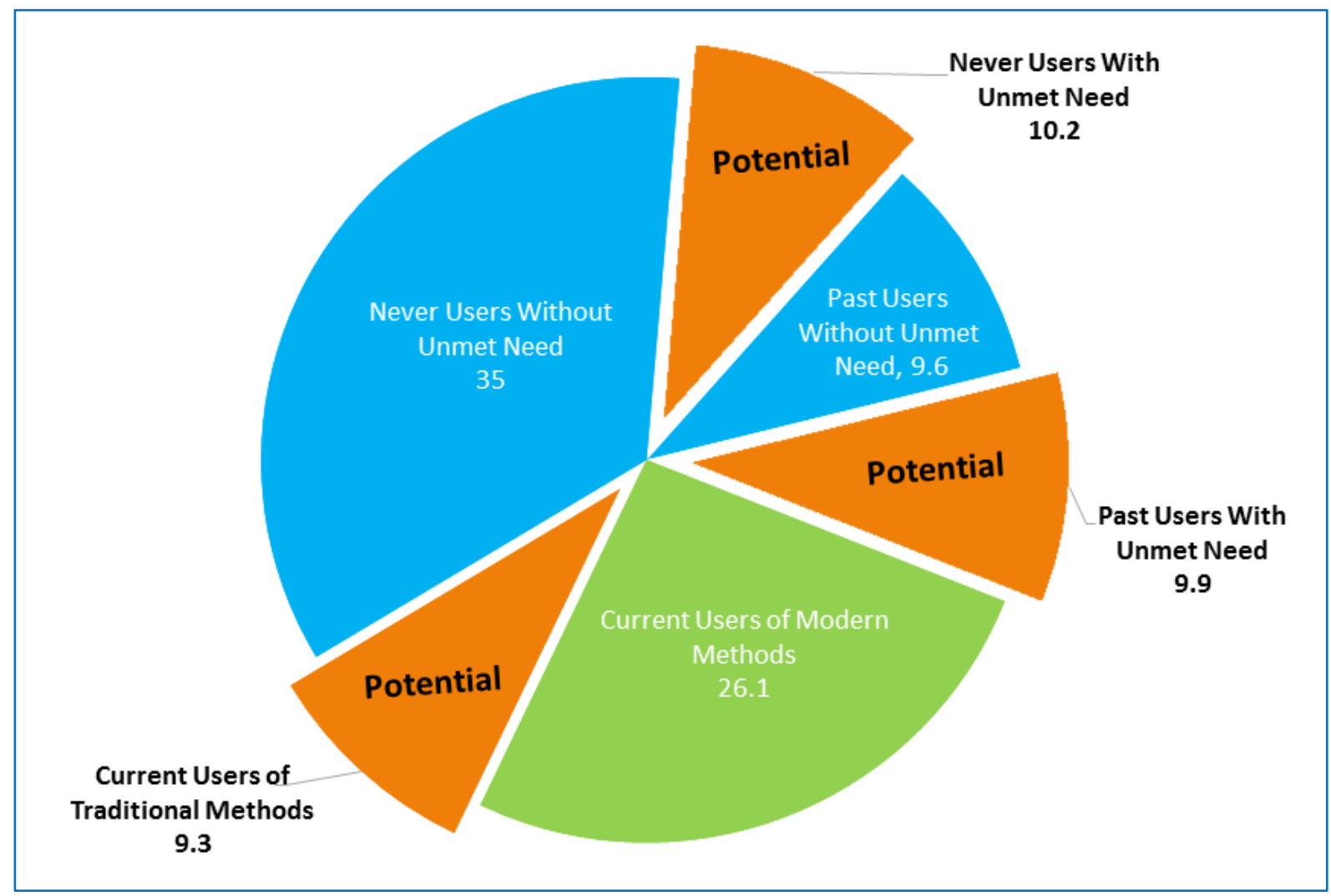

Source: Pakistan Demographic and Health Survey 2012-13

In terms of family planning experiences and perspectives, the 9 million potential users in the market comprise three distinct segments.

- Never users with unmet need are relatively younger (median age of 29), have 1 to 2 children, and are mostly uneducated and poor. An estimated 3.1 million women comprise this category, of whom $24 \%$ live in urban areas.

- $\quad$ Past users with unmet need are the oldest segment (median age 35), have the highest parity (4+ children), and are also mostly uneducated. However, they are represented across all wealth quintiles. They are estimated to number 3 million, with 33\% based in urban areas.

- Traditional users with unmet need have a median age of 33 and most educated (secondary level) segment, and mostly in the higher wealth quintiles. They have 2-4 children. Comprising an 
estimated 2.9 million women, this is the most urbanized segment, with $46 \%$ living in towns and cities.

- Current users of modern methods, like users of traditional methods, belong to higher wealth quintiles, are educated beyond primary level, and $41 \%$ are urbanized. They tend to be older and have higher parity.

\section{Each segment of potential users faces unique barriers, with implications for programming.}

- For never users with unmet need, the primary reasons for non-use are (1) lack of information, especially among men; (2) low access to health services, especially in rural communities not served by Lady Health Workers (LHWs); and (3) fear of side effects of modern contraceptives.

"I didn't know about condoms. I saw some people buy them at a shop. I asked the retailer about them and mentioned that I have small children and want to use the product. They said its price is just Rs. 20 and you can use it. So I purchased it but didn't use it because I didn't know how."

Male, Multan city

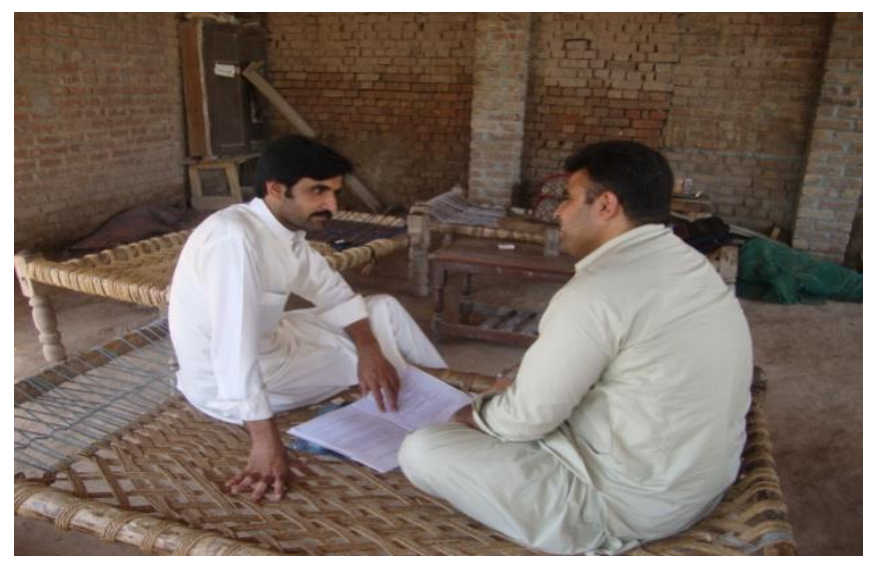

"I took this method from a private lady doctor. The government hospital is very far away and treatment is not satisfactory there. They treat women like animals and do not give proper attention. In the private clinic, everything is nice and easy."

Female, Karachicity

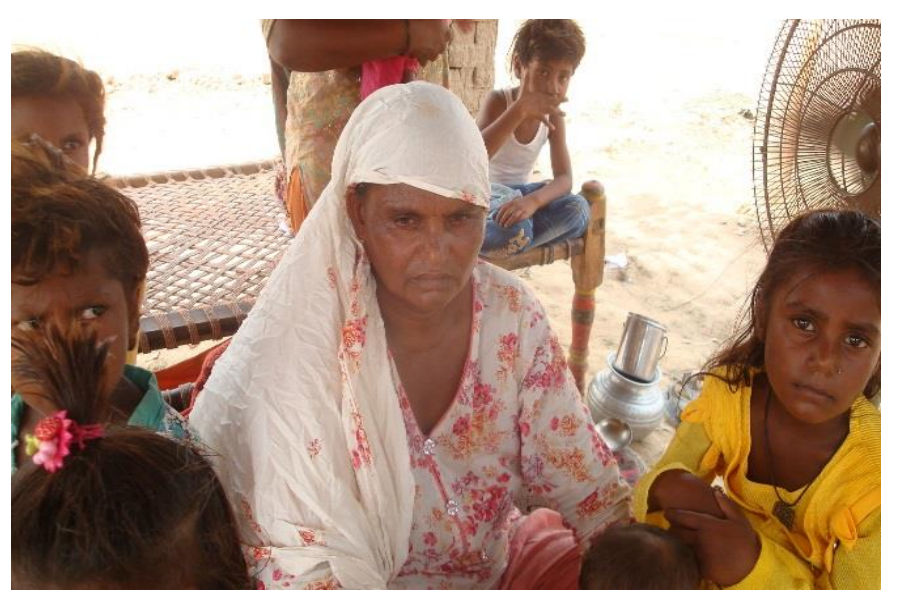

- Among past users with unmet need, the most entrenched barrier is (1) past experience of debilitating side effects, coupled with (2) experience of low-quality, unsupportive health services, and (3) potential high costs of side effect management.

- Among traditional method users, (1) fear of side effects is a main barrier to modern contraceptive use, along with (2) lack of method-specific information.

- While religious misperceptions continue to exert a negative influence, mainly in Khyber Pakhtunkhwa, they do not comprise the decisive hurdle for potential users. 


\section{Use of contraceptives is positively associated with awareness and female employment, and more likely to commence at certain life points.}

- Contact with LHWs is a strong ideational factor in rural areas, while the mass media has influence in both urban and rural areas.

- Use is likely to start after the birth of one child among urban couples and two children in rural areas, as well as at each successive birth.

- Urban couples are more driven by economic concerns and rural couples by health issues.

\section{Due to side effects, many current users of modern methods teeter on the brink of discontinuation; special efforts are required to retain them in the market.}

- Many current users are completely satisfied or face only mild side effects, but a significant proportion are persevering despite severe side effects and their physical, emotional, financial, and social toll.

- Unless they receive sound counseling and information to manage and cope with side effects (and try other methods), it is unlikely that they will be able to sustain use.

"The experience (of IUD) is good in the sense that it gives long-term spacing and also gives relief from the tension of bearing more children. But I have side effects. I have infection, and such severe back pain, it's a problem washing clothes. I am forced to use this method because my children are young and my husband is also in favor of two children. We have little income so we cannot afford more children." Female, Peshawar rural

\section{Men and women say they want:}

- Detailed, method-specific information, preferably through community workers, information materials, the Internet, social media, and mobile phone services;

- Honest and informed communication to allay fears about side effects and highlight health benefits of contraceptive use, preferably through community meetings, mass media, and service providers;

- Accessible and affordable services through providers who have contraceptives on hand and know how to manage side effects. In particular, there are strong calls for doorstep delivery of services through trained, equipped Lady Health Workers (LHWs), and male providers for men. People also demand public and private facilities in their vicinity, with separate spaces for men and women to obtain nominally priced services, especially for side effect management.

- Safe access to new methods, with men more interested in the Standard Days Method (SDM) and women in Sayana ${ }^{\circledR}$ Press due to relative privacy and fewer or no access issues. Implants are generally viewed negatively on account of possible side effects. 


\section{The outlook is bright; young people's response to family planning is a resounding Yes!}

- Adolescents have a very positive view about family planning and express unqualified readiness to adopt it regardless of gender, schooling status, and rural/urban residence.

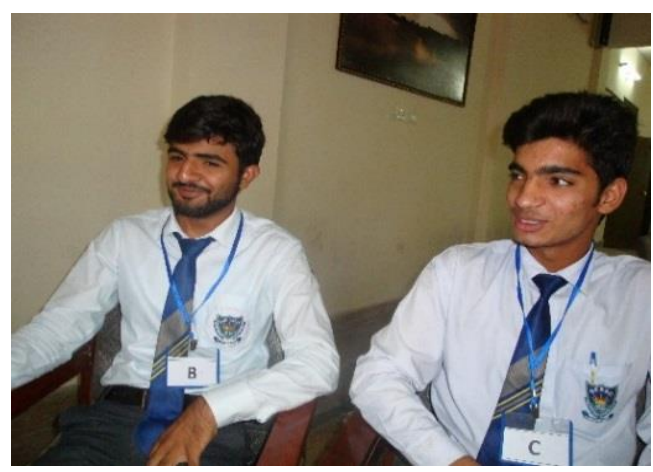

"I will be fearless in using FP methods because this will mean my family is healthy, the children are educated and fed." In-school boys, Karachi city

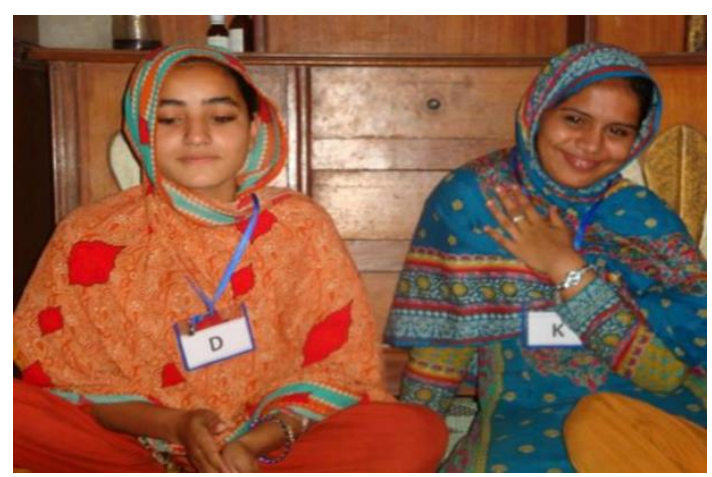

"I see my father sweat at the loom all day and even then it is hard to make ends meet. I think to myself, it's because we are eight. If we were four children, it wouldn't cost so much." Out-of-school girls,

Faisalabad rural

- Boys and girls consider family planning to be important and necessary for maternal and child health, better care of children, better schooling opportunities for children, and to afford expenses more easily.

"How could you not space children? It is essential for health...To be a happy family, it is necessary to have fewer children and to space them." Out-of-school girls, Sukkur rural

- Compared to young girls, boys are better aware of specific methods, and generally have more access to mobile phones, as well as to wider social networks beyond family members. On the other hand, more girls watch television.

- Both young girls and boys want information on family planning, provided accurately and privately, preferably through the Internet, social media, and mobile messages, including audio/visual material for the uneducated. Girls especially suggest promoting family planning through TV and radio programming in local languages.

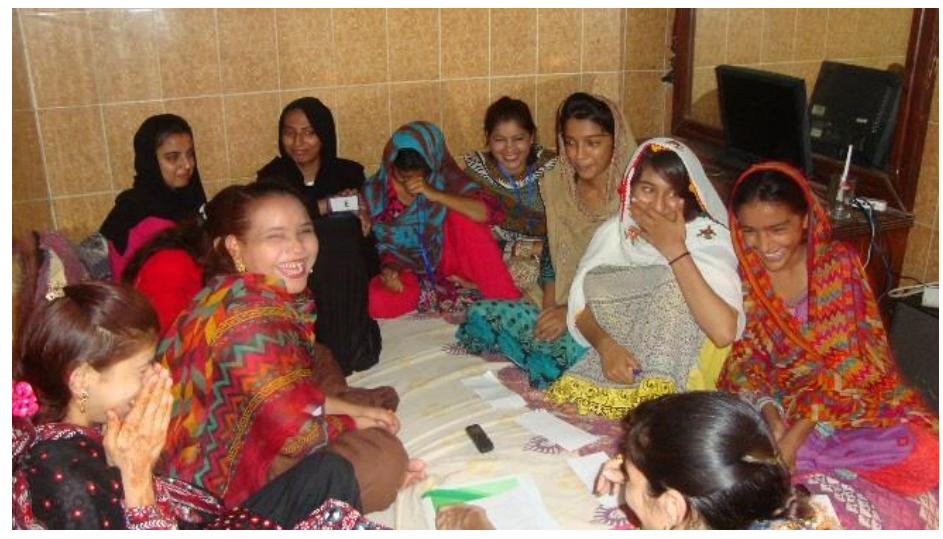




\section{Provision of Family Planning Services and Barriers to Growth1}

\section{While the numbers and distribution of health facilities and pharmacies are impressive, relatively few are offering any family planning service, even in the explicitly mandated public sector.}

- In the public sector, a much higher proportion of Population Welfare Department (PWD) and People's Primary Healthcare Initiative (PPHI) facilities are providing family planning services than facilities of the Department of Health (DoH). On the other hand, DoH has a much larger clientele, since it has a larger network and provides a wider range of health services.

- Among the much more numerous private health facilities, only $41 \%$ of urban providers and $29 \%$ of rural providers are providing family planning services.

- A higher share of pharmacies offer family planning products-69\% in urban and $53 \%$ in rural areas--but the majority only sell condoms and oral contraceptive pills.

Census of Static Health Facilities, Community-based Workers and Pharmacies in the Study Districts

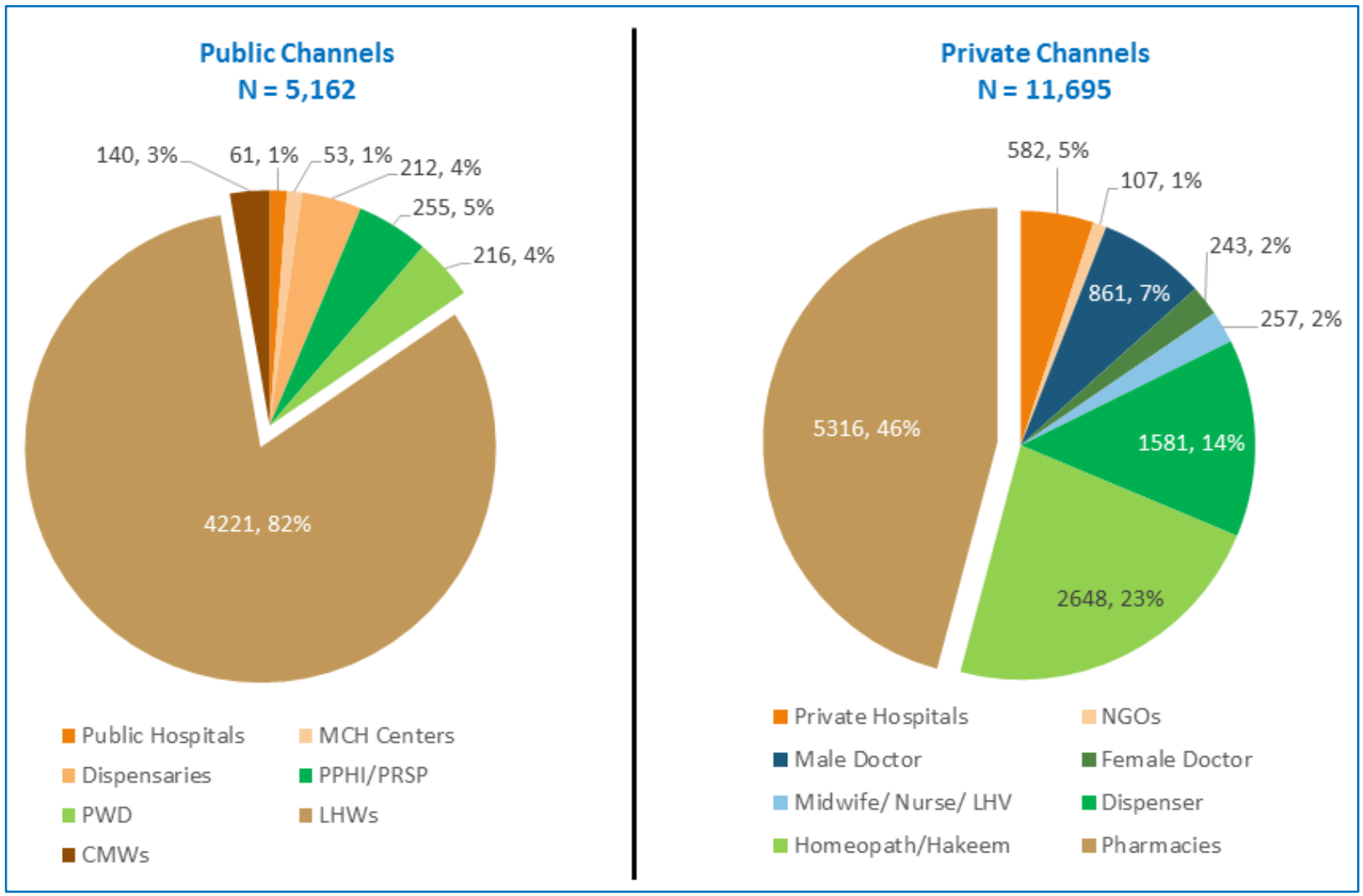

${ }^{1}$ This analysis is based on the mapping and assessment of health facilities carried out in four highly urbanized districts, including Faisalabad and (three towns within) Lahore in Punjab, Peshawar in Khyber Pakhtunkhwa, and Sukkur in Sindh. 
Family Planning Service Provision among Static Facilities, Community-based Workers, and Pharmacies

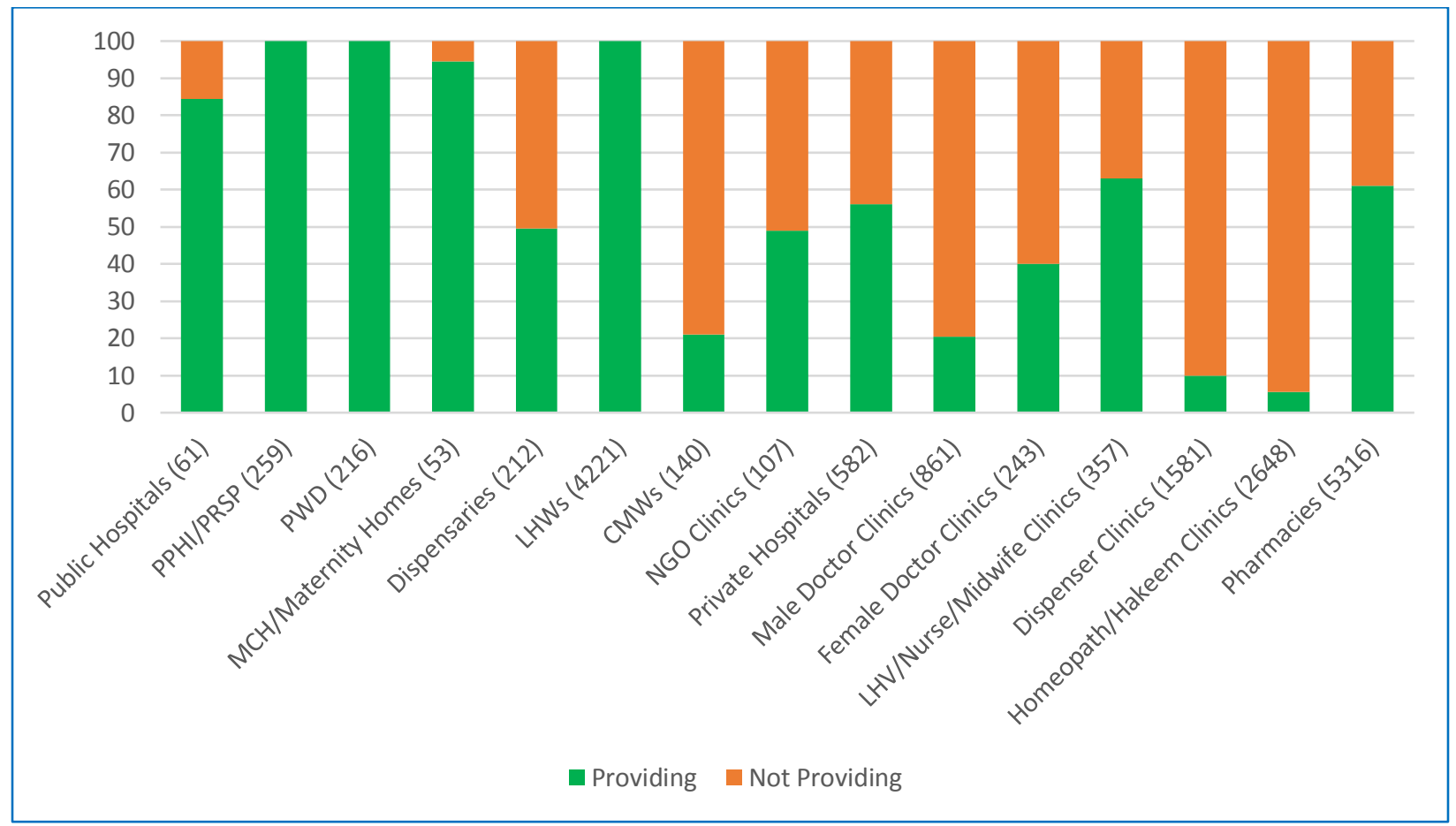

The choice of family planning methods available is highly limited at most health facilities and pharmacies.

- In the public sector, condoms and oral contraceptive pills are widely available across the major channels but figures dip for injectables and emergency contraceptive pills.

- The range of family planning services at DoH facilities is largely limited and needs to be expanded. PWD also needs to increase provision of emergency contraceptive pills in both urban and rural areas.

- Only $10 \%$ of private facilities in urban areas and even fewer in the rural areas are providing a combination of condoms, oral contraceptive pills, injectables, and emergency contraceptive pills.

- Across pharmacies in rural areas, 38\% stock condoms, 29\% stock oral contraceptive pills, $8 \%$ stock emergency contraceptive pills, and only $17 \%$ carry injectables. In urban areas, $54 \%$ stock condoms, $52 \%$ stock oral contraceptive pills, 31\% stock emergency contraceptive pills, and $32 \%$ carry injectables.

- Notably, the quality of care is perceived by most men and women to be better at private facilitiesalthough facility readiness was observed to be generally better in the public sector, provider behavior is reported by clients to be much better in the private sector. 
Percent of Facilities Providing 3+ Methods in the Study Districts $(\mathrm{N}=1036)$

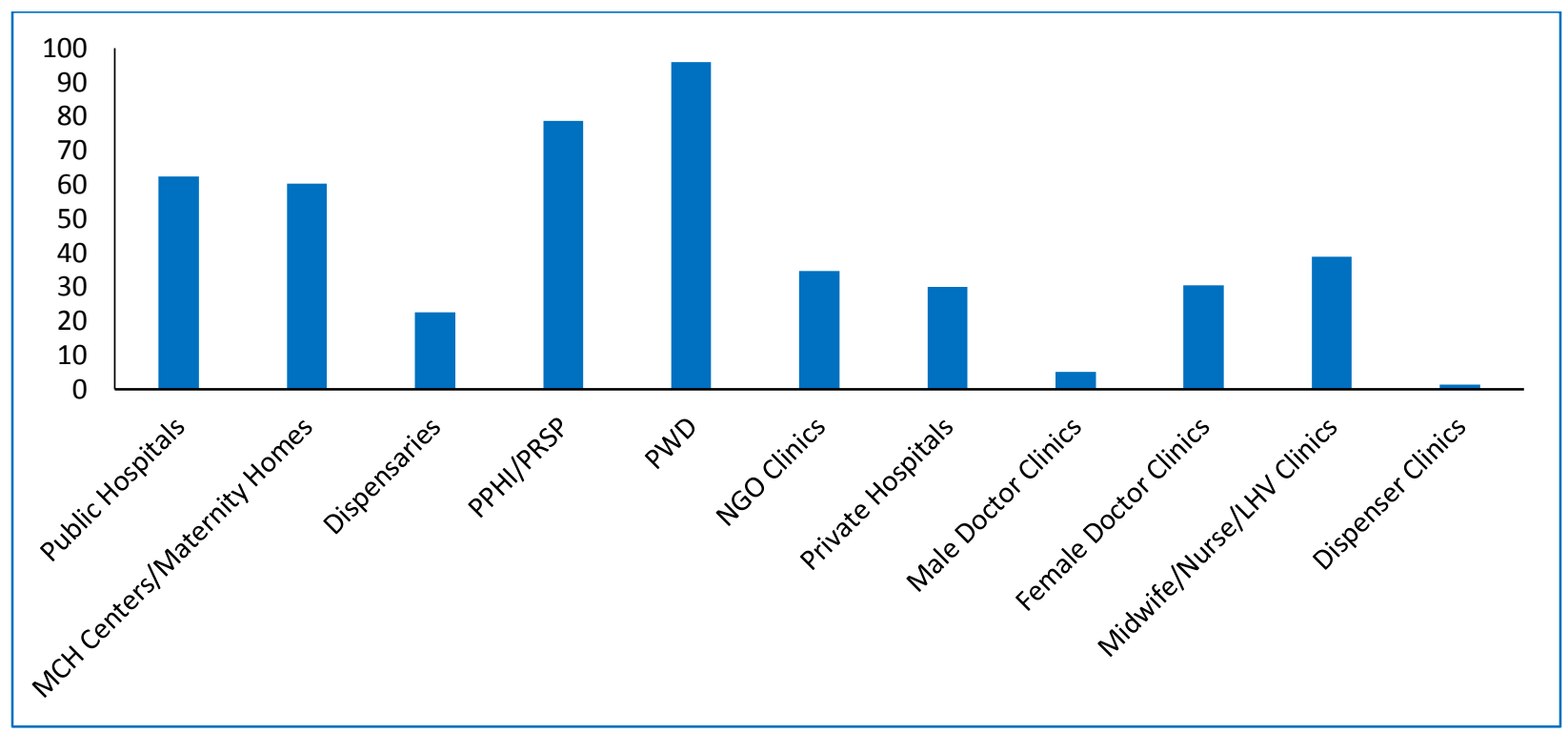

In terms of numbers and spread, the most widely accessible channels are pharmacies, LHWs, and private non-physician and traditional providers (i.e., Lady Health Visitors [LHVs], nurses, midwives, dispensers, hakeems, and homeopaths).

\section{Comparison of Distribution of Health Facilities in District Faisalabad}

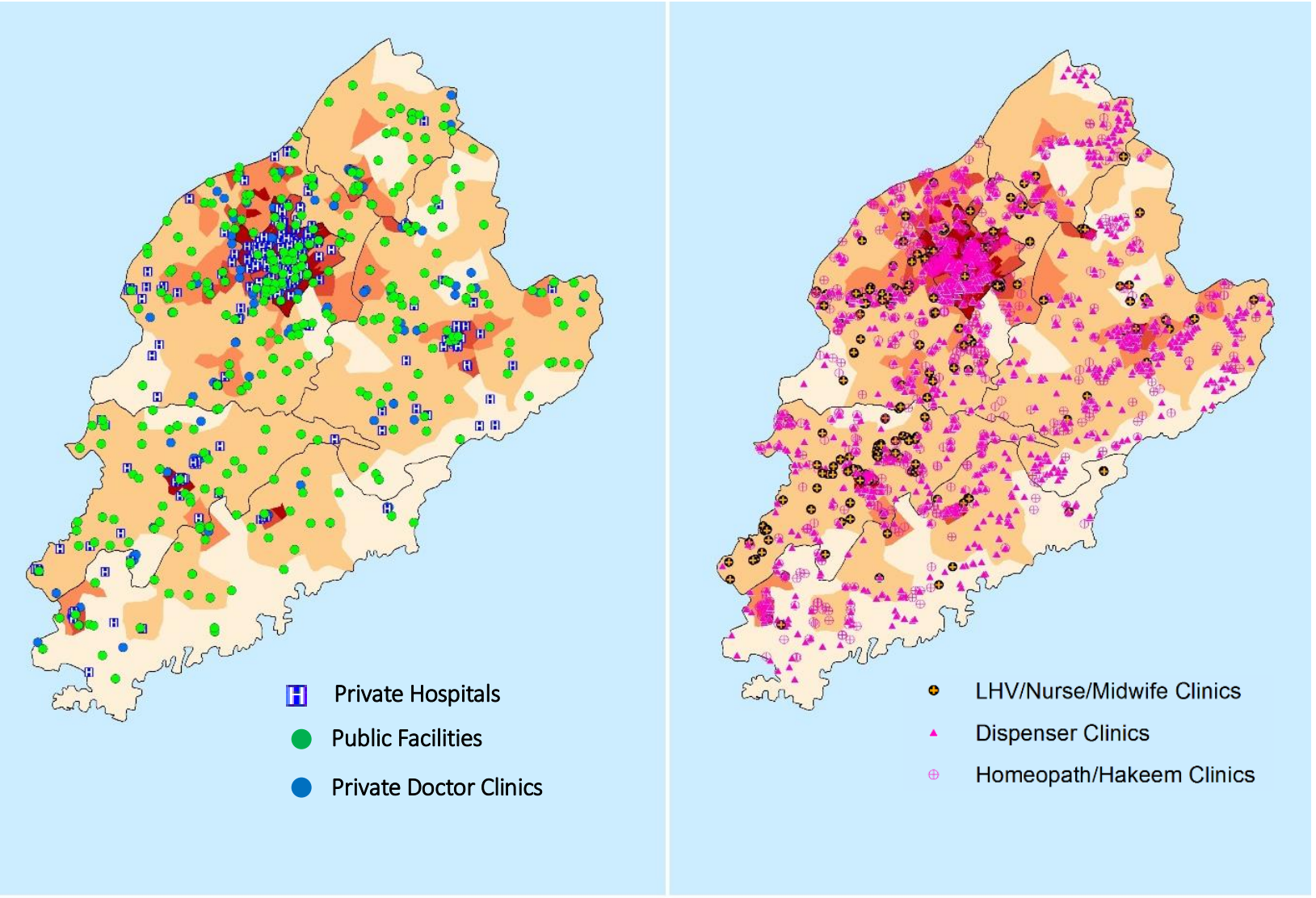


Non-physician and traditional cadres are restricted from providing certain family planning methods (although some offer services nevertheless).

- LHWs are not allowed to administer the first dose of injectables and do not provide emergency contraceptive pills.

- Among male providers, dispensers are not allowed to provide any family planning services, though they are widely present and respected in rural areas, although hakeems and homeopaths have very recently been permitted to offer some family planning methods in Punjab.

- Commercial, NGO, and social marketing suppliers of contraceptives are all of the view that, mid-level cadres are a more widely present and more motivated channel to focus on.

Other key barriers to service provision include poor or non-supply of a method, low motivation due to perceived lack of demand, and lack of capacity to provide the method or manage its possible side effects.

- The barriers are mentioned by both public and private providers.

- In interviews during the qualitative study of supply, private providers also cited perceived cultural nonacceptance of male providers, lack of financial motivation--especially among doctors, and doubts about the religious permissibility of family planning.

- The frequency with which specific barriers are cited varies across methods, provider types, and rural/urban residence. 


\section{Challenges in Supply of Contraceptives}

Consumers' main sources of contraceptives are pharmacies, shops, and commercial/NGO hospitals in the private sector.

- Pharmacies are a key source of condoms, oral contraceptive pills, and emergency contraceptive pills, but have a very low role in providing injectables, IUDs or implants

- Shops only sell condoms.

- Private/NGO hospitals are leading sources of injectables and IUDs.

In the public sector,consumers rely most on LHWs and larger public hospitals.

- LHWs are major sources for condoms, oral contraceptive pills, and injectables.

- Public hospitals are major sources of injectables, IUDs, and oral contraceptive pills.

Condoms are the only method for which weobserve the expected pattern of wealthier clients preferring the private sector, and poorer clients preferring public sources; for all other methods, usage by wealth is mixed.

Both public and private health facilities most frequently cite lack of supply or non-availability of methods as the reason for not providing most specific methods.

- In the public sector, contraceptive stock outs remain common at facilities across all subsectors.

- Both urban and rural facilities are affected, the latter report the issue more frequently.

- Roughly half of all public health facilities are not providing injectables, IUDs and implants, and over three quarters of those are not providing ECPs and condoms because of supply constraints.

- In the private sector, the large numbers of small health facilities are not a part of any distribution system.

"We have separate social organizers to supply products to the CMWs, in project-based rural settings... Distributors do not supply directly to our clinics, so we manage through our own sales teams. It is a challenge." An SMO representative

- Absence of distribution channels for private providers is especially problematic for methods that are barely available at pharmacies.

- Providers have to be motivated to purchase from pharmacies, or be served by the medical information officers (MIOs) of contraceptive manufacturers/importers to have stocks available.

Provincial governments have started to procure contraceptives, but the public contraceptive supply chain may facesome transition-related issues.

- Earlier research found key requisitioning delays, lack of transport arrangements for delivery from district stores to facilities, rationing of supplies, especially in the case of LHWs; and inadequate use of electronic reporting systems, among others.

- Interviews indicate a need to develop procurement capacitiesacross all these areas in the provincial governments.

- The large NGOs previously served by the public contraceptive supply may not be catered under the new provincial arrangements, raising costs significantly. 


\section{Separate supply chains operate in the private sector, differing by method.}

1. Condom brands are all imported, by commercial as well as social marketing organizations (SMOs).

- This is the only method supplied to shops.

- While the private condom market is maturing, commercial importers complain it is difficult to compete against SMOs, especially with the subsidized products and high profit margins to retailers.

- Some importers do not use consumer goods distribution channels, restricting coverage of shops.

- Numerous small brands of varying quality are also smuggled into the country.

\section{Supply of Condoms in the Private Sector}

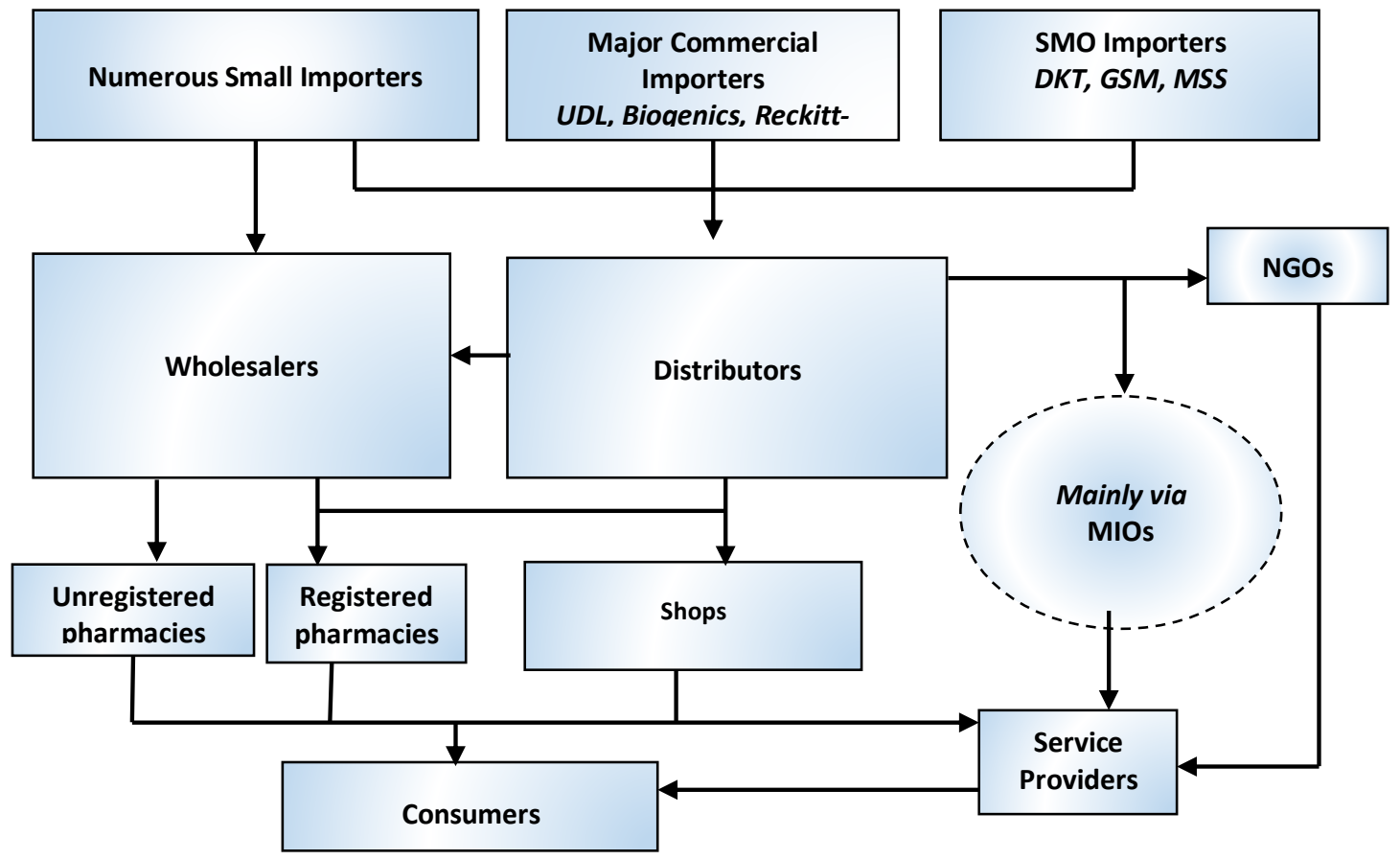

2. OCPs, ECPs and injectables in the market are mainly locally manufactured and distributed to health facilities and pharmacies.

- Sales of these hormonal methods are low, mainly attributed to low demand due to side effects.

- The need to address consumer fears about side effects is acknowledged by all, but the challenge is not owned by commercial or social marketing entities.

- Import of products is restricted, and there is a narrow range of producers, products, and pricing options.

"Users of traditional methods are growing even among urbanized, well-educated and wealthier segments; even the religious people are supporting traditional methods. The educated people think: why should they introduce alien materials in their body? We do not have a strong communication strategy for modern methods in our country. We need to introduce modern methods through strong influencers and clear messages." SMO representative 
3. The long-acting reversible methods (LARCs), IUDs and implants, are mainly imported by SMOs and supplied to health facilities, with a very low presence at pharmacies.

- Private supply of IUDs and implants is mainly restricted to providers catered by SMOs/NGOs.

- Low demand is also a constraint for suppliers; fears about side effects are perpetuated by inadequate counsel and follow-up care.

"If donors require that we push IUDs, we push the program to achieve that target. Providers don't even counsel clients much or provide them all the facts about IUDs. Theoretically, they give them a choice, but they push the long acting methods. That can eventually lead to discontinuation." SMO representative

In terms of numbers and distribution (and potentially also willingness) pharmacies have the greatest potential for expanding access to contraceptive products.
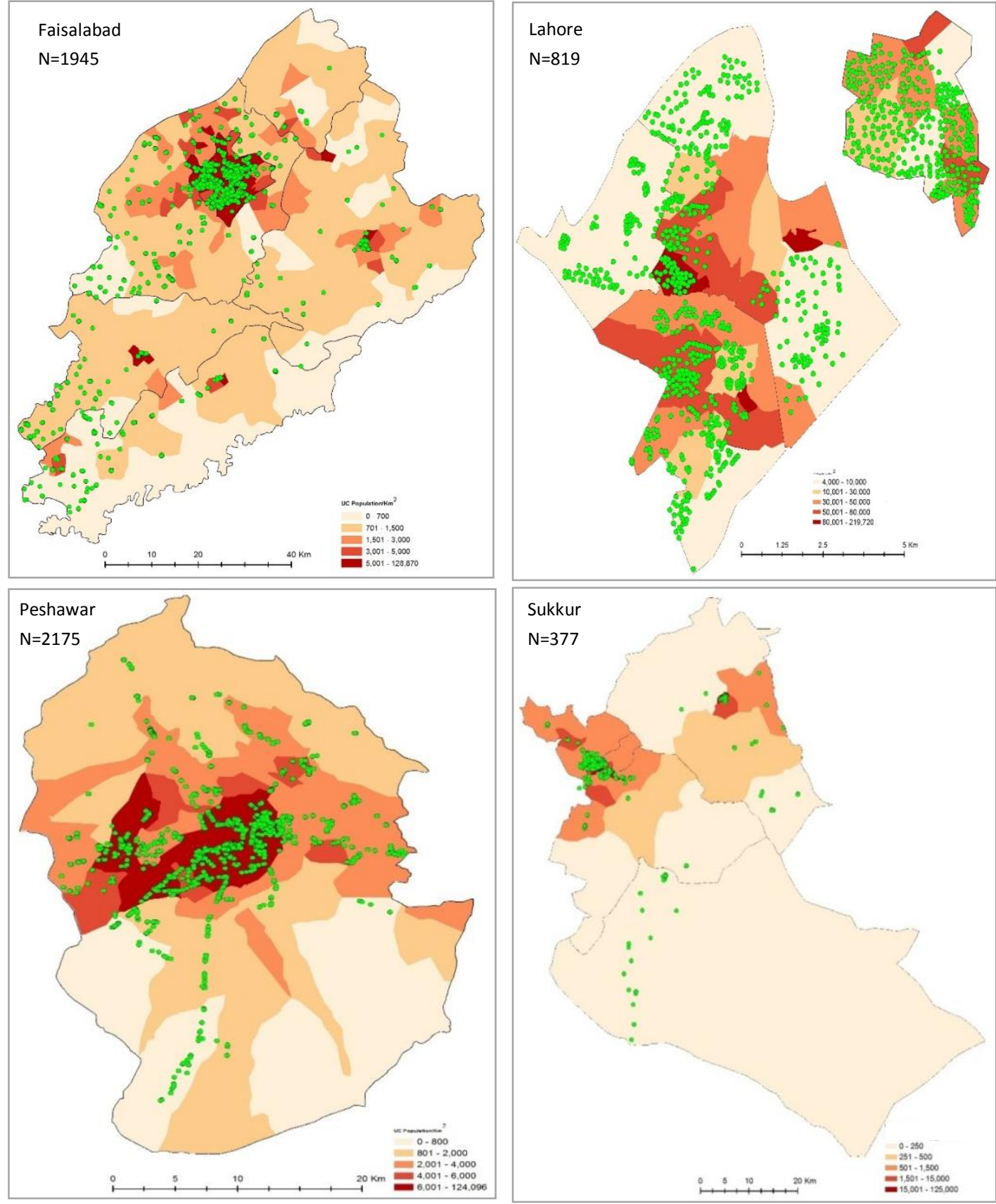
"Pharmacies are approached by males and youth and therefore the staff of pharmacies must possess adequate family planning knowledge and counseling skills to guide and prescribe appropriate method." Pharmacist, urban Faisalabad

However, the barriers preventing pharmacists from selling contraceptives proactively will need to be overcome.

- While many pharmacistsare willing and eager to play a role in informing and counseling clients, significant proportions don't sell contraceptives, mainly citing supply constraints, as well as insufficient demand and doubtsabout religious permissibility of family planning.

Pharmacists' Reasons for not Selling Family Planning Products in Study Districts ( $\mathrm{N}=\mathbf{2 1 2 7})$

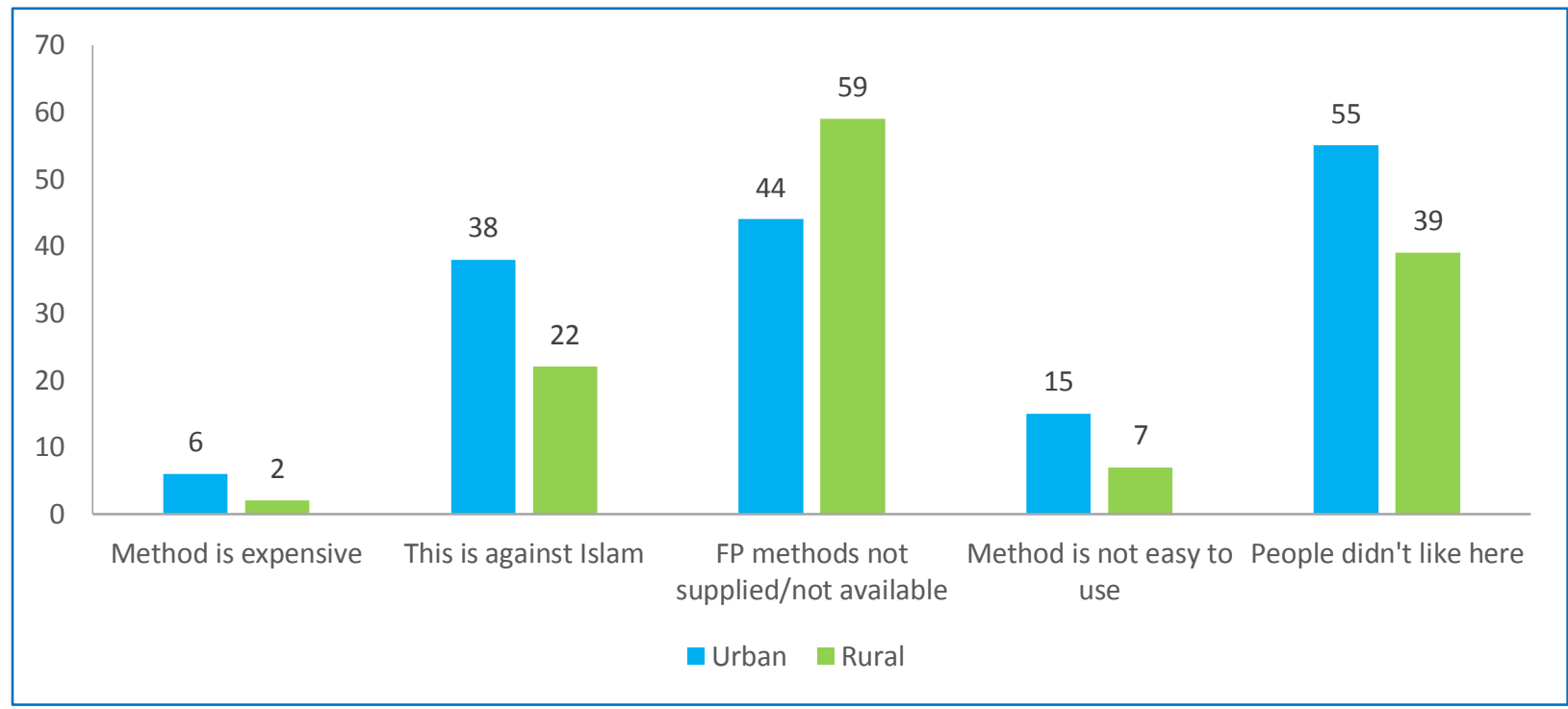

There are large numbers of unlicensed pharmacies, which cannot be catered for by distributors and have to procure contraceptives through wholesalers, often reducing profit margins and increasing costs.

- Distributors have a low interest in supplying rural areas, where the market is diffused, and rural pharmacists therefore complain more frequently of stock-outs and having to purchase from wholesalers. 


\section{Policy Landscape and Investments in Family Planning}

Post the $18^{\text {th }}$ Amendment, provinces have demonstrated many positive changes to accelerate efforts to improve access to family planning services.

- There is visible provincial political commitment, including from Chief Ministers, and provinces have set their own FP2020 CPR goals.

- Provinces have in place family planning-focused policies, and some have or are developing family planning costed implementation plans.

- Provincial health strategies also give due importance to delivering family planning services.

While the population policies and health/development strategies of Punjab, KP and Sindh have several important strengths, they also suffer from some gaps.

- Modalities for expanding contraceptive choices, reaching out to the rural poor, informing and serving youth, and involving the private sector are not indicated.

- Ways to improve synergy with the Health Department, such as task shifting and task sharing, and to ensure uninterrupted supply of contraceptives are not specified.

- There is overemphasis on infrastructure expansion and too little attention to improving quality.

- Accountability mechanisms are not elaborated.

- Metrics are based on process rather than outcome indicators.

- In some cases, targets in strategies do not concur with population policies.

There is an urgent need to focus on implementation of policies.

- Current ownership of the family planning mandate is concentrated with the PWD, with limited infrastructure and capacity and resource constraints--

- There has to be visible sharing of responsibility across sectors.

- Coordination amongst departments, especially the population welfare and health programs, is weak, leading to suboptimal complementarity and occasional duplication of efforts.

- Stronger coordination mechanisms are needed to act synergistically, monitor progress, and make necessary adjustments to achieve goals. 
Comparison between Health and Population Provincial Budgets/Accounts of Punjab, Sindh and KP for FY 2013-14 to 2014-15

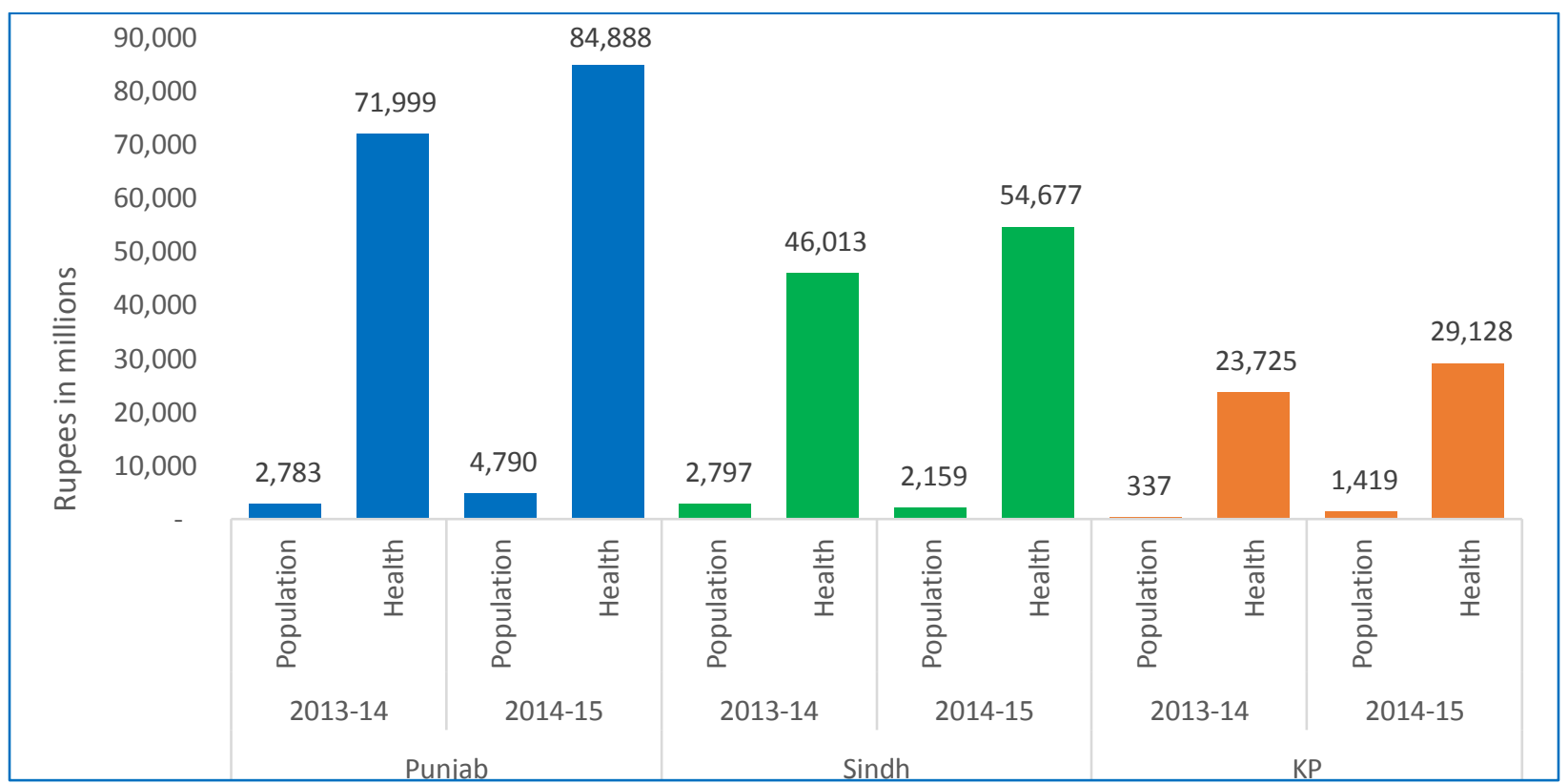

Government Spending on Family Planning Per Capita in US Dollars has gone up in Punjab, KP and Sindh.*

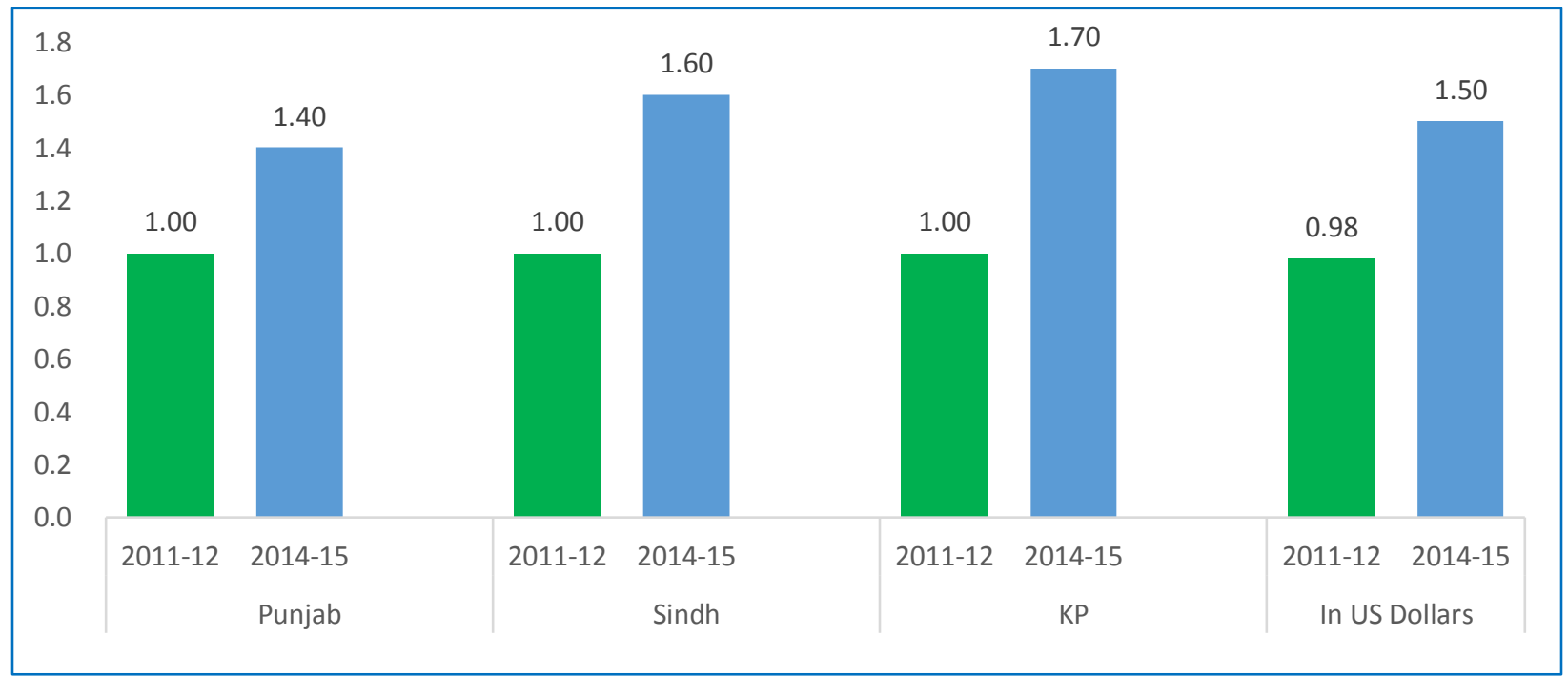

- Through provincial funding the provinces have initiated a number of activities such as trainings of providers establishing new RTIs and increasing the number of FWCs.

- The three major provinces are allocating more of their own resources for family planning services.

- At the moment, the lion's share of allocations that can be utilized for family planning is in the provincial health programs.

- Very recently, the provincial population welfare programs have increased their allocations for the procurement of contraceptives, mainly for the public sector.

* To estimate the total public outlay on FP for the major three provinces we are assuming that the full Population Welfare budget, 33 percent of the LHW budget, 10 percent of the $\mathrm{MNCH}$ budget, and 10 percent of the provincial health budgets all collectively contribute to directly funding FP we see a rise in the overall outlay for FP for the three provinces from 15.3 billion rupees to 27.6 billion presents per capita allocations based on population projections. 
While donors are supporting Pakistan and some provinces in particular in meeting their family planning goals, specific family planning spending is not so notable and uneven investments leave some provinces with limited funds for family planning.

\section{Donor Investment in RH Including Family Planning: (in \$ millions)}

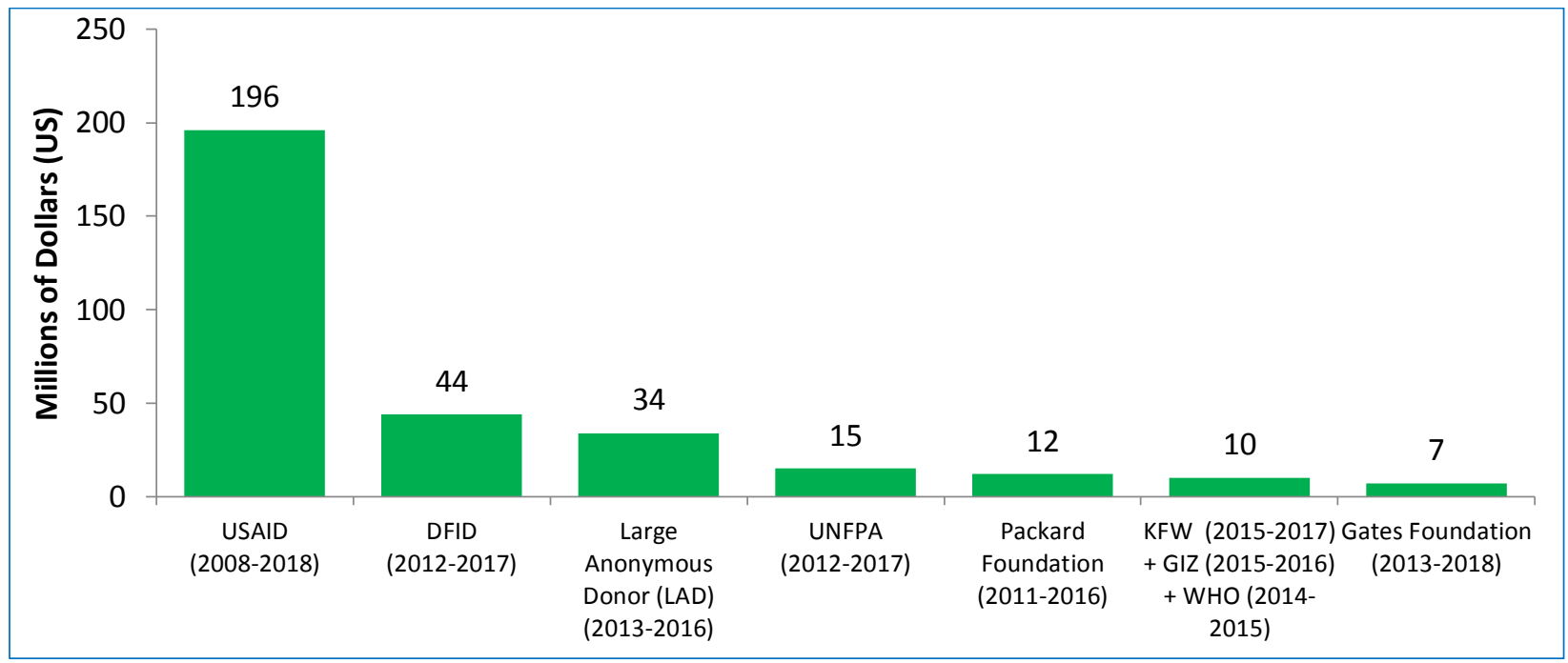

Donor funding of 318 million 2009-19 comes to 45 million per year. This shows donor contribution of $17 \%$.

\section{Location of Relevant Donor Interventions in Pakistan}

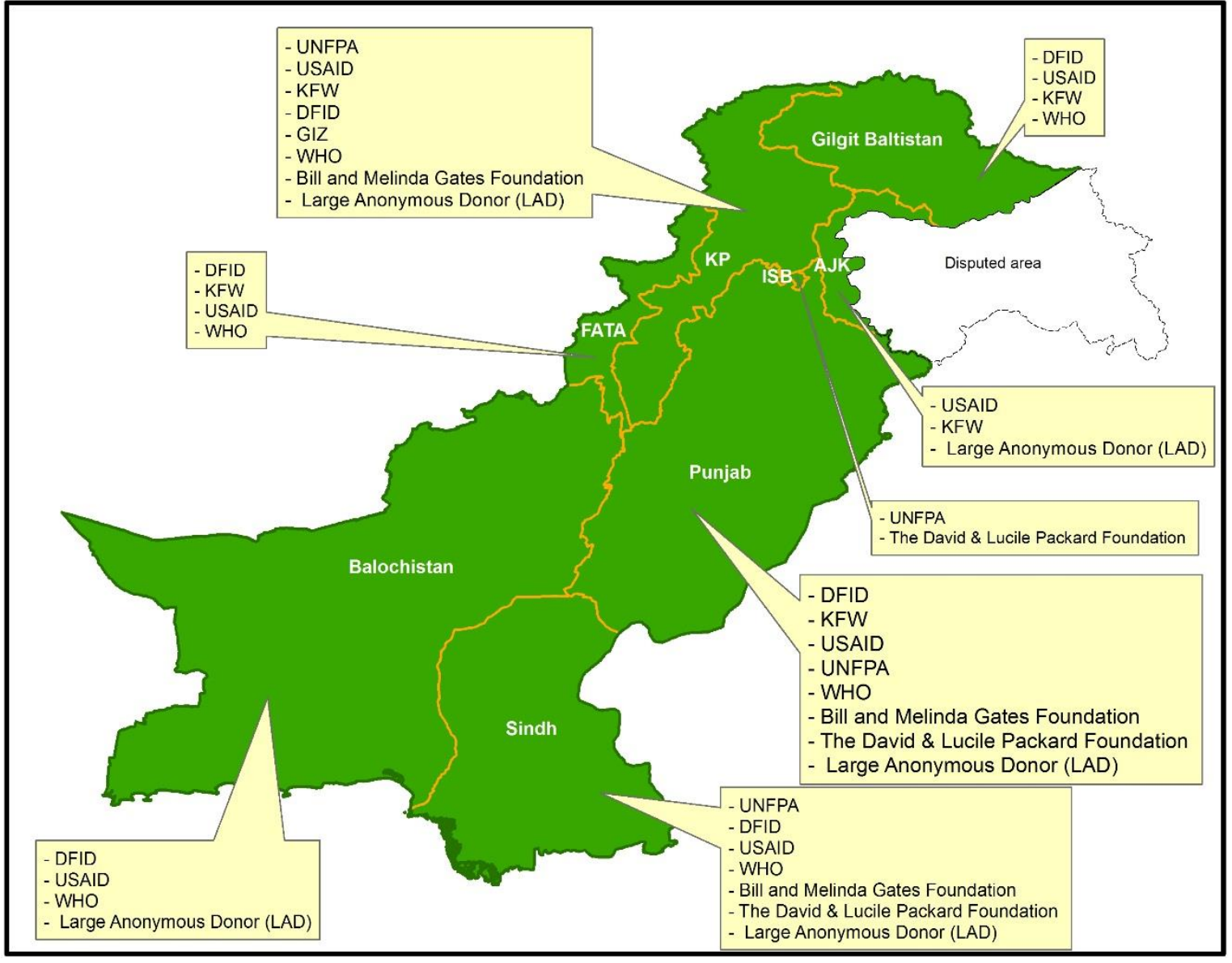


As the provinces accelerate efforts to reach their FP2020 goals, they face a number of challenges:

- Nearly $40 \%$ of areas are not covered by LHWs, posing a major obstacle in achieving universal access to family planning services, which will require a well thought-out strategy to resolve.

- While the provincial policies acknowledge a role for the private sector in delivering family planning services, mechanisms to operationalize private sector provision remain unresolved.

- Communications efforts, especially in terms of reaching out to men and youth, are weak.

- Provincial capacities need to be improved, particularly for preparing Annual Development Plans (ADPs), and for designing innovations. 


\section{Recommended Areas for Investment}

On the basis of the wide ranging findings of this extensive situation analysis of the family planning landscape, we propose a range of investments to overcome the communication and information gaps that perpetuate suboptimal use and provision of family planning services; expand access to family planning services through task shifting, greater participation of private and male providers, and improved quality of care; expand contraceptive choices for consumers through introduction of new methods, task shifting, and improved mechanisms for contraceptive supply; and drive the required evidence-based policy changes to upscale successful initiatives.

\section{Launch a transformative communication strategy targeting all stakeholders}

We strongly recommend a comprehensive communication campaign designed not only to meet the awareness and information needs of consumers, but also to galvanize the health community, pharmacists, commercial suppliers, and policymakers at all relevant levels. The strategy should meet the specific needs identified for various segments of potential users in the landscape analysis. It should moreover capitalize on the recent endorsement of birth spacing by Pakistani religious leaders, and also tap into multiple channels-combining interpersonal communication with the powerful potential of mass media and social media in the country.

\section{Catalyze private service provision to expand access}

Private sector providers generally outnumber public sector providers, and consumers express preference for private facilities for reproductive healthcare. Increasing private sector involvement is also necessary especially in areas that are underserved by the public sector. In this regard, we propose measures to reinvigorate a focus on family planning in the health community in both sectors; improve policies and mechanisms to encourage, guide, and monitor private provision; identifying priority regions for private provider involvement through mapping; train private providers to provide safe family planning services, mainly through Regional Training Institutes of the Population Welfare Department; and to incentivize private providers through special arrangements such as the emerging Punjab Population Innovations Fund.

\section{Conduct implementation research and advocacy for task shifting to midlevel providers,} male providers, and traditional providers to expand access as well as choice

Mid-level providers are more motivated and widely available channels (especially in rural areas) for family planning provision. Moreover, involving male providers could be a game changer in view of men's high interest in family planning. We recommend implementation research to test out a number of promising task shifting ideas, which can be used as evidence to convince policymakers to permit additional cadres as well as new methods, such as provision of first dose of injectables, emergency contraceptive pills (ECP), and the Standard Days Method (SDM) via LHWs; provision of oral contraceptive pills, ECP, and injectables by trained homeopaths and hakeems, and by dispensers linked with doctors, etc.

\section{Groom pharmacies as the first stop for family planning advice and counseling}

Pharmacies are quite widespread and an important potential source of not only contraceptive commodities but also information and counsel for men and women. To stimulate this channel we propose a communication campaign to remove pharmacists' doubts about the religious permissibility of family planning, and apprise them of the many forms of latent demand in the market. We also recommend 
training pharmacists to reach out to shy or reluctant customers, to provide counseling and information about specific methods, and encourage them to offer a wider range of methods.

\section{Introduce new methods while ensuring high quality of care}

Women and men in Pakistan are open to trying out new methods, and introducing these could expand choice and inject new enthusiasm about contraception. However, any new method will need to be introduced with accompanying high quality counseling and services. We recommend an implementation science approach to rolling out new methods, specifically the Standard Days Method (SDM) and Sayana ${ }^{\circledR}$ Press, which were both well received by men and women, to ensure that the needs of quality counseling and side effect management are met and the demand is retained.

\section{Build provincial governments' capacities for supply chain management}

In the public sector, persistence of high levels of contraceptive stock out indicates the importance of continuing efforts to improve the contraceptive supply chain. Investments could be considered in areas such as building capacity to ensure that the Logistics Management Information System (LMIS) is fully utilized for improved reporting, monitoring, and decision-making; building capacities and improving processes for forecasting and procurement at all levels; and improving storage arrangements at provincial and district level.

\section{Identify innovative solutions to ensure delivery of contraceptives to the last mile}

We recommend stakeholder dialogue coupled with implementation research to identify innovative solutions for ensuring that contraceptives reach health facilities. In the public sector, the need for health facilities to collect supplies from district stores should be minimized through ideas such as the informed push model of contraceptive supply piloted recently in Senegal. Clusters of smaller private health facilities could be linked with pharmacies.

\section{Support commercial marketing and distribution of condoms}

Condom import has attracted considerable commercial interest, which can be harnessed for efficient and sustainable market expansion. A major commercial importer expressed interest in launching a low-cost but full-priced condom brand, with initial support for marketing, as a commercial substitute for subsidized products. Support could also be provided by incentivizing distribution of condoms to rural areas and through consumer goods channels, which are currently underutilized by some commercial importers.

\section{Improve quality of counseling and method provision}

The landscape confirms huge discontinuation, particularly of modern contraceptive methods, driven to a great extent by untreated side effects and lack of information among users. Since stemming this leakage of consumers is at least as important as taking new users on board, we recommend a range of interventions. These include development/adoption of standard protocols and guidelines for provision of specific family planning methods, especially counseling, information provision, management of side effects, and follow-up; training of providers; and research to identify priority elements of quality of care necessary to improve continuation rates, based on provider and client perspectives. This can be used to develop quality standards, and monitoring and accountability mechanisms. We also recommend a shift from CYP-centered approaches in programming to a greater emphasis on measuring and prioritizing retention of users/methods. In the public sector, accountability could be improved by enabling clients to send SMS-based complaints about service providers to a monitoring cell, and linking performance appraisals of providers with client feedback. 


\section{Mainstream ownership of the family planning mandate in the health system}

A most compelling need is for the public health system to be more responsive and take greater responsibility for the provision of family planning services as a routine and regular part of its mandatory services. Post-partum family planning, antenatal and postnatal checkup and post abortion care must be utilized as opportunities, as they are currently often overlooked by overworked and pressed health care providers. Effective partnership between the Population Welfare Department and Department of Health could include expanded timings in the public sector and setting up of separate family planning service centers within all public health outlets.

\section{Develop a multi-sectoral coordination mechanism for provincial policy implementation and underpin strategies with strong monitoring, evaluation and learning}

At the policy level, provincial governments, powerful medical and professional bodies, and donors need to work together to ensure that resources both human and financial are made available and significant programmatic changes do occur. This will require political will and commitment and enhanced accountability at all levels within a multi-sectoral framework. The existing coordination forums, with their heavy reliance on the Population Welfare Department, should be replaced by a platform headed preferably by the Chief Secretary of the province. Mechanisms must also be instituted for strong monitoring and evaluation of programming to gauge progress at provincial and district levels, and implementation research conducted to test the feasibility of new interventions and guide their upscale.

\section{Prioritize family planning at the highest policy levels and in investments}

Population issues more broadly and family planning more specifically, must be included in all deliberations at the federal and provincial levels with regards to the wider development agenda and strategies. We recommend that donor investments in family planning be pooled for concerted action on jointly identified priorities. The advantages of folding family planning into maternal and child health programs should be carefully weighed against the risks of compromising focus on this important preventive measure within a host of other competing-and ultimately linked-issues of delivery, child survival and malnutrition. 